\title{
Diabetes education mobile APP prototype for Hispanic communities
}

\author{
Amanda J. Harris, Amy E. Fathman \\ University of Cincinnati, Cincinnati, Ohio, USA
}

Received: December 20, 2019

Accepted: March 22, 2020

Online Published: April 2, 2020

DOI: $10.5430 /$ jnep.v10n7p26

URL: https://doi.org/10.5430/jnep.v10n7p26

\begin{abstract}
When compared with the general United States population, Hispanic Americans are at an increased risk of developing type 2 diabetes mellitus (DM2) and are far more likely to suffer devastating complications related to the disease. The purpose of this quality improvement project was to determine whether the use of a culturally tailored, mobile application prototype educational tool increased DM2 prevention knowledge among Hispanic patients at risk for DM2. The educational tool contained information about DM2 including risk factors, prevention, and health maintenance. The prototype was developed to function like a working mobile application and a pre/posttest was administered to participants at three local Hispanic community health fairs in Cincinnati, Ohio. Paired $t$ test analysis of the 27 completed surveys showed a statistically significant improvement in posttest scores. The results showed that the average score was 4.1 out of a total of five possible points in the pre-test. The mean total score of the post-test was 4.7 , with a total improvement of the mean score of $0.6(0.0001)$. It was concluded that there was a statistically significant improvement in the knowledge of DM2 prevention after reviewing the material presented in the application prototype. In addition, participants expressed a strong interest in a working mobile application that offers culturally tailored DM2 prevention education.
\end{abstract}

Key Words: Diabetes prevention education, App-based health education, Hispanic health

\section{INTRODUCTION}

According to the Centers for Disease Control and Prevention (CDC), Hispanics are more likely to develop type 2 diabetes mellitus (DM2) in their lifetime and 50\% more likely to die from DM2 related complications than the general United States (US) population. ${ }^{[1]}$ Ethnic, socioeconomic and local environmental factors keep Hispanic Americans from getting the tools, screenings, and treatment that they need to lower their risk factors. ${ }^{[2]}$

The key to addressing prevention disparities is finding ways to effectively communicate risk reduction lifestyle modifications in a way that is understood within the cultural framework of the target population. In multiple studies, culturally tailored educational interventions have been shown to be effective in increasing disease prevention knowledge among Hispanics. ${ }^{[3,4]}$ In addition, the use of mobile applications as platforms for health information has been shown to be a valuable means for increasing patients' access to health information. ${ }^{[5]}$ Still, there is a need for tailoring applications to be more usable by diverse patient populations. This project combined a culturally tailored education tool with a mobile application prototype to increase access to DM2 prevention information for Hispanic Americans.

\section{BACKGROUND}

\subsection{Review of literature}

The need to create solutions to address the health outcomes disparity for Hispanics at risk for DM2 is well documented

*Correspondence: Amanda J. Harris; Email: harri2a3@mail.uc.edu; Address: University of Cincinnati, Cincinnati, Ohio, USA. 
in the literature. ${ }^{[3-7]}$ Hispanic patients are known to have less access to DM2 screenings and preventative care which is a large factor that potentiates the disparities in disease complications for this population. ${ }^{[6]}$ Developing effective educational tools that focus on disease prevention is crucial to improving DM2 outcomes for Hispanic Americans. Culturally tailored approaches have been shown to be more effective than standard teaching methods across multiple studies. ${ }^{[3,4]}$ Furthermore, studies investigating the use of social media and other electronic sources as a platform for health education have shown that these mediums are effective for teaching important health topics. ${ }^{[8]}$ A mobile application that is easily accessed from a computer or a mobile device provides an excellent source for communicating culturally tailored DM2 education materials.

Considering the use of electronic tools as platforms for health education is key for providers trying to communicate with an ever-diversifying patient population. Specifically, advanced practice nurses (APNs) can use electronic resources to engage and clearly communicate with patients. Although cultural differences can create barriers to shared decision making between providers and patients, it is important to recognize opportunities to bridge that communication gap. According to a study by Govere \& Govere, cultural training for providers significantly increased patient satisfaction with their care. ${ }^{[7]}$ Considering the cultural needs of a target audience prior to conducting educational programs is an effective way to improve patient-provider communication. Culturally tailored tools readily available for providers may allow for improved and standardized health education interventions for Hispanic patients.

Like all providers in today's healthcare landscape, APNs must effectively utilize technology to optimize their clinical practice. Healthy People 2020 outlines a goal to "use health communication strategies and health information technology to improve population health outcomes and health care quality, and to achieve health equity." ${ }^{[9]}$ By increasing use of technology, APNs have the opportunity to decrease barriers that patients encounter when trying to access health information. Previous research has shown that social media and secure short message service (SMS) text messaging are effective ways to improve communication between providers and Hispanic patients. ${ }^{[10]}$ Combining technology with culturally tailored information has the potential to make valuable information available instantly on a mobile device.

\subsection{Population focus}

Across the US, Hispanic immigrants have been found to have lower literacy and numeracy than other immigrant groups, and it has been shown that these lower literacy levels cor-

Published by Sciedu Press relate with lower self-reported health. ${ }^{[1]}$ In designing an educational tool for this population, it was crucial to take into account literacy and education levels. A study evaluating the Hispanic immigrant population using federally qualified health centers in the Midwest found that $61 \%$ of Hispanic immigrants held education levels less than 7 th grade. ${ }^{[12]}$ The education tool developed in this project took into account the potentially limited health literacy of the target population and focused on a simple language and picture-based teaching technique.

Specifically, this project focused on creating an education tool for Hispanic immigrants in the greater Cincinnati, $\mathrm{OH}$ area. According to the US census bureau, Cincinnati's population of 302,000 contains about 3.1\% Latinos. ${ }^{[13]}$ However, the population is concentrated in certain areas of the city in the neighborhoods of Price Hill and Carthage, where Hispanics make up 5\% and $23 \%$ of the community respectively. ${ }^{[14,15]}$ Two organizations located in these communities collaborated on this project. These organizations facilitated access to a growing Hispanic population, most of whom were noted by the organizations to have only recently immigrated to the US.

\subsection{Theoretical and conceptual framework}

Stemming from Dorthea Orem's Theory of Self-Care, the project sought to increase self-care capacity through education about healthy lifestyle and diet choices related to DM2 prevention. According to Orem's theory, the role of nursing care is to meet a patient's self-care deficit. In other words, do for the patient what they cannot do for themselves. Through education, a nurse can help patients increase their health knowledge and ability to care for themselves. ${ }^{[16]}$ The overarching goal of this project was to empower Hispanics to make better lifestyle and diet choices based on increased knowledge of healthy behaviors by creating a tool that would increase the self-care capacity of participants.

The project was implemented according to the Plan, Do, Study, Act model. The model allows for planning of measurements, processes, and objectives to be established prior to the intervention. Then, the intervention can be carried out, results studied, and findings applied to policy change or further research. ${ }^{[17]}$ This project moved through the "plan, do, study" portion of the research model and has outlined ways in which the "act" phase can lead to future development of a working mobile application available to Hispanic patients at risk for developing DM2.

\section{STRATEgY AND IMPlEMENTATiON}

Implementation of this project was accomplished in three phases: presentation of the educational tool, administration 
of the pre/posttest evaluation tool, and evaluation of the intervention through paired $t$-test analysis. First, an educational mobile application prototype for DM2 prevention combining technology with culturally tailored information was developed. Through partnerships with regional Hispanic community organizations, the intervention was implemented during three separate health fairs in the Cincinnati area from January through April, 2019. Health fairs gathered walking crowds of 100 to 200 people at each event. A booth was set up and the educational materials were made available to any willing passersby. Participants were gathered through a convenience sampling of self-selected individuals. Participants then accessed the app prototype through the Marvelapp TM website and used click links to navigate the site as if it were a working mobile application. The information from the prototype was also displayed on large poster boards, and a handout of the Más o Menos (More or Less) page was given to participants to take home with them after the health fair.

\subsection{Educational tool}

The educational tool was created by the authors on the website, Marvelapp.com ${ }^{\mathrm{TM}}$ as a prototype of a mobile applica-

\section{Todo Lo Que Debes Saber Sobre la Diabetes Tipo 2}

Que es la diabetes?

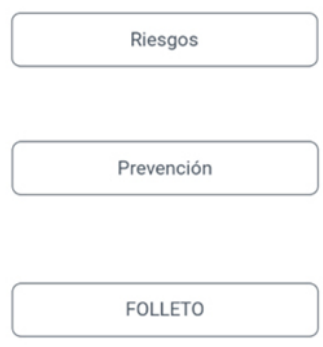

tion. Click links allowed participants to navigate the prototype as if it were a working application. The prototype included many pictures and simple language so that it could be understood with minimal Spanish literacy. All information in the tool was based on guidelines from the American Diabetes Association and the American Heart Association. ${ }^{[18,19]}$ The homepage was titled "Everything You Should Know About Type 2 Diabetes" and included links to four additional pages (see Figure 1). The page links were titled, "What is Type 2 Diabetes?", "Risks", "Prevention", and "Handout." The page titled "What is Type 2 Diabetes" included basic information on DM2 (see Figure 2). Paragraph one stated, "The pancreas is the organ of the body that produces insulin, the hormone that helps the body convert sugar to energy." The second paragraph further explained, "In type 2 diabetes, the cells of the body do not respond well to insulin, and the sugar that you eat remains in the blood." The final paragraph stated, "High levels of sugar in the blood cause damage to all the systems of the body including the nerves, veins, kidneys, and eyes."

\section{Everything You Should Know about Type 2 Diabetes}
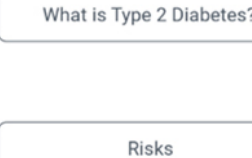

Prevention HANDOUT

Figure 1. Prototype Home Page 

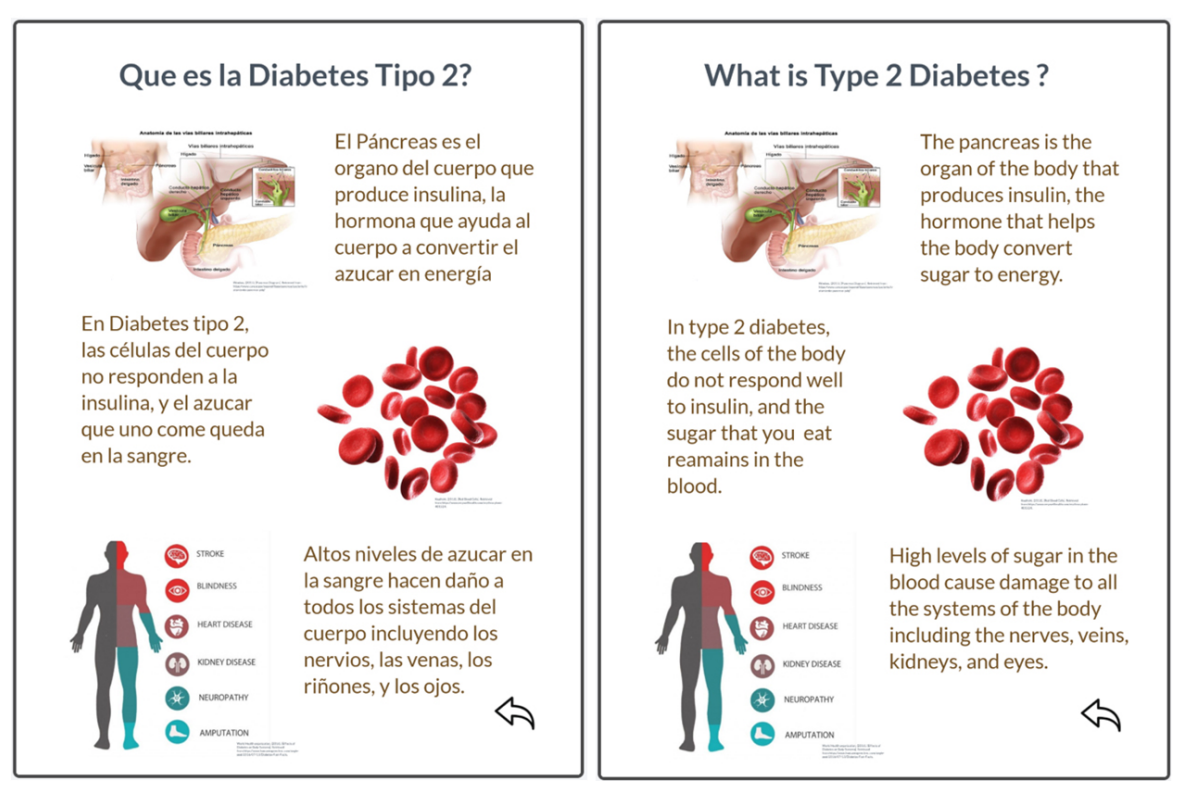

Figure 2. Prototype DM2 Information

The page titled "Risk Factors for Type 2 Diabetes" listed the following risk factors for DM2: "age greater than 45 years, being overweight, family history of type 2 diabetes, high blood pressure, a history of gestational diabetes, and not exercising at least three times a week" (see Figure 3). This page also cited information from the CDC stating, "Latinos are at an increased risk of developing type 2 diabetes in their lifetime and are 50\% more likely to die from type 2 diabetes related complications than the general population." The "Diabetes Prevention" page provided instruction about the positive impact of lifestyle, diet, and regular medical care on DM2 prevention (see Figure 4). The English translation of this page is as follows: "Lifestyle: be more active, exercise

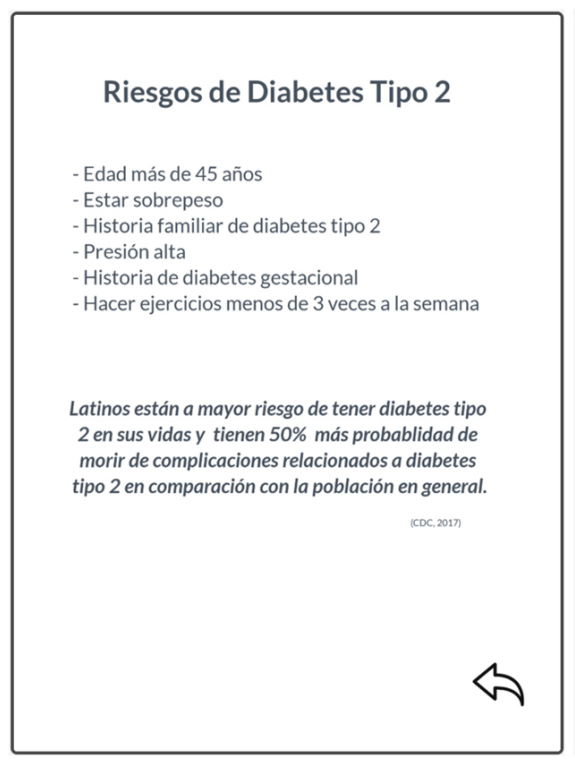

Figure 3. Prototype DM2 Risk Factors

Published by Sciedu Press
30 min, five times a week; Diet: Eat five fruits and vegetables every day, avoid drinks with lots of sugar and foods with lots of fat; Medical care: get a regular physical and blood testing". The final page of the application prototype contained a chart titled "Más o Menos" "(More or Less)" which outlined behaviors a person should add and reduce in their lifestyle in order to lower their risk for developing DM2 (see Figure 5). This page was created by the authors with the help of a local artist who made icons for each of the actions outlined by the text. The prototype educational app was specifically and intentionally developed to convey simple ideas using pictures so that the material could be easily understood by participants regardless of their Spanish literacy level.

Risk Factors for Type 2 Diabetes

- Age greater than $45 y e a r s$

- Being overweight

- Family history of type 2 diabetes

- High blood pressure

- History of gestational diabetes

- Not exercising at least 3 times a week

Latinos are at an increased risk of developing type 2 diabetes in their lifetime and are $50 \%$ more likely to die from type 2 diabetes related complications than the general public. 

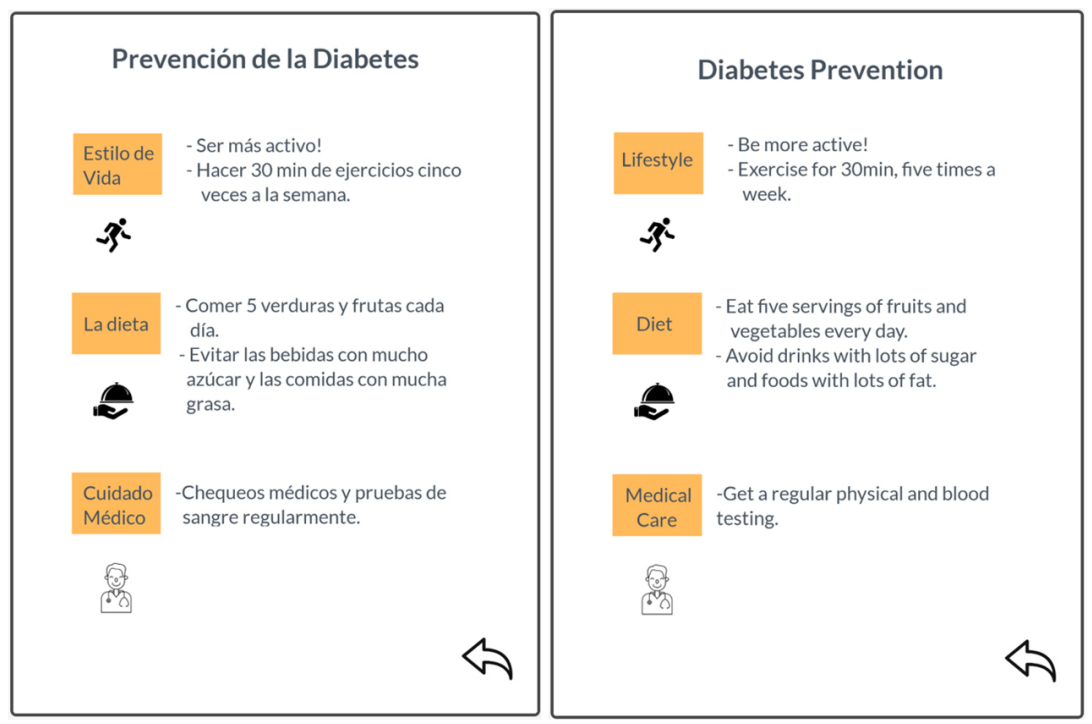

Figure 4. Prototype DM2 Prevention

\begin{tabular}{|l|l|}
\hline MÁs & MENOS \\
\hline $\begin{array}{l}\text { Hacer ejercicios } 30 \text { minutos, cinco veces a la } \\
\text { semana (Exercise } 30 \text { min five times } \\
\text { a week) }\end{array}$ & $\begin{array}{l}\text { Televisión, videojuegos, tiempo enfrente de } \\
\text { la pantalla (TV, video-games, } \\
\text { screen time) }\end{array}$ \\
\hline $\begin{array}{l}\text { Agua } \\
\text { Water) }\end{array}$ & $\begin{array}{l}\text { Soda \& Jugo } \\
\text { (Pop \& Juice) }\end{array}$ \\
\hline $\begin{array}{l}\text { Granos integrales } \\
\text { Whole grains) }\end{array}$ & $\begin{array}{l}\text { Tortillas blancas, galletas, } \\
\text { arroz blanco } \\
\text { (White flour tortillas, } \\
\text { cookies, white rice) }\end{array}$ \\
\hline $\begin{array}{l}\text { Comidas horneadas } \\
\text { (Baked foods) }\end{array}$ & $\begin{array}{l}\text { Comidas fritas } \\
\text { (Fried foods) }\end{array}$ \\
\hline $\begin{array}{l}\text { Ferduras como lechuga, } \\
\text { tomates, zanahorias, y } \\
\text { (Fijoles } \\
\text { tomatoes, carrots, beans) }\end{array}$ & $\begin{array}{l}\text { Puike lettuce, } \\
\text { (Chips, takis, cheetos) }\end{array}$ \\
\hline
\end{tabular}

Figure 5. Prototype Más o Menos (More or Less) Page 


\subsection{Pre/Post test evaluation tool}

The evaluation tool utilized for this project was a pre/posttest that included questions about basic demographics and healthy diet and lifestyle choices. It also included questions to evaluate interest in a mobile application for DM2 education and contained one open-ended question to evaluate what other information participants believed should be included in teaching materials for DM2 prevention (see Figure 6).

1. Latinos están a mayor riesgo de tener diabetes en sus vidas en comparación con el público en general.

a. Cierto

b. Falso

2. ¿Cual es una buena elección de grano integral?

a. Lechuga

b. Papas fritas

c. Arroz blanco

d. Pan integral

3. La "American Heart Association" recomienda minutos de ejercicio de moderado

intensidad cinco veces a la semana

a. 10

b. 15

c. 30

d. 120

4. "Me siento capaz de identificar comidas bajas en azúcar y grasa?"

a. Cierto

b. Falso

5. Si esta información fuera disponible en una aplicación móvil, la utilizaría usted?

a. Sí

b. No

6. ¿Cual es una cosa que quisiera usted saber acerca de la prevención de diabetes?
Self-selected participants answered three demographic survey questions on age, gender, and ethnicity (see Figure 7). Age in years was divided into the following categories: $<16$, 16-25, 26-35, 36-50, 51-65, and >65. Gender options included: "Male, Female and Other," and ethnicity options included, "Caucasian, Hispanic, Asian, African American, and Other."

1. Latinos are at greater risk of having diabetes in their lifetimes compared with the general public.

a. True

b. False

2. What is a good choice of whole grain?

a. Lettuce

b. French Fries

c. White Rice

d. Whole wheat bread

3. The American Heart Association

recommends__ minutes of moderate

intensity exercise five times a week.

a. 10

b. 15

c. 30

d. 120

4. "I feel able to identify foods low in sugar and fat."

a. True

b. False

5. If this information was available to you in a working mobile application, would you use it? a. Yes

b. No

6. What is one thing you would like to know about diabetes prevention?

Figure 6. Pre/Post Test Evaluation Tool

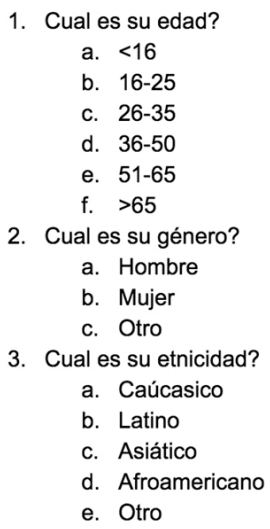

Figure 7. Demographic Survey

Participants then answered the pretest questions on a paper form prior to reviewing the information provided in the educational tool. Approximately 20 minutes after reviewing the materials, participants completed the posttest. Each pre and posttest was assigned a number in order to anonymously

1. What is your age?
a. $<16$
b. $16-25$
c. $26-35$
d. $36-50$
e. $51-65$
f. $>65$
2. What is your gender?
a. Male
b. Female
c. Other
3. What is your ethnicity?
a. Caucasian
b. Hispanic
c. Asian
d. African American
e. Other

associate responses with the correct participant. The first three questions on the pre/posttest were objective questions assessing knowledge about DM2 prevention. The fourth and fifth questions, "I feel capable of identifying foods low in sugar and fat: True or False," and "If this information was available to you in a working mobile application, would you use it?" were subjective questions evaluating the participants self-reported knowledge of types of food impacting DM2 prevention and willingness to use a fully developed mobile application to obtain information about DM2 . One open-ended question allowed for collection of qualitative data on other information participants would like to learn about DM2.

\section{Results}

\subsection{Demographics}

At total of 44 surveys were collected across the three health fairs. Of those, seventeen incomplete responses were excluded, leaving twenty-seven responses available for analysis. 
Completed surveys revealed that all participants included in the sample were Hispanic. The majority (89\%) of participants identified themselves as female, and $11 \%$ identified as male. The age in years of participants was divided into categories with $19 \%$ ages $16-25,33 \%$ ages $26-35,30 \%$ ages $35-50$, and $18 \%$ ages $51-65$. There were zero respondents in the $<16$ and $>65$ age brackets.

\subsection{Pre/Post test}

Paired sample $t$-test compared responses to questions one through five from pre to posttest. The mean score was 4.1 out of a total possible five points on the pretest. The mean total posttest score was 4.7 , with a total mean score improvement of $0.6(p<.0001)$ showing statistically significant improvement in knowledge of DM2 prevention after reviewing the material presented in the application prototype. A breakdown of the number of correct responses on the pre and posttests is provided in Table 1.

Of the knowledge-based questions one, two, and three, question three was the most commonly missed on the pretest and showed a statistically significant improvement in mean score of $0.4(p<.0001)$. Answers to the subjective question number four were considered "correct" if participants responded "true" to being able to select foods low in sugar and fat. Question five responses were considered correct if they selected "yes" to being interested in using a mobile application with DM2 education materials. Question four, which evaluated self-reported ability to make healthy lifestyle choices showed a modest but statistically significant mean increase of 0.1 ( $p$ $<$.04). Question five, which sought to evaluate participant interest in using a working mobile application for DM2 education showed no statistical difference from pre to posttest responses $(p=.163)$.

Table 1. Number of correct responses on pre and posttests

\begin{tabular}{lll}
\hline & Pretest \# of correct answers & Posttest \# of correct answers \\
\hline Q1 & 26 & 27 \\
Q2 & 18 & 19 \\
Q3 & 15 & 26 \\
Q4 & 24 & 27 \\
Q5 & 25 & 26 \\
\hline
\end{tabular}

\subsection{Open ended responses}

Participants expressed an interest in learning more about DM2 prevention in their responses to the single open-ended question, "What is one thing you wish to learn about diabetes prevention?". Responses included phrases like, "More information on the symptoms of diabetes and how to recognize it," "What is considered a high blood sugar?", "How do I control my diabetes?", and "Everything possible!". These responses revealed participants' desire for more in depth education of both prevention and management of DM2.

\subsection{Limitations}

The small sample size and gender homogeneity of participants precluded generalizability of findings to the US Hispanic population as a whole. Limited Spanish literacy encountered in a number of potential participants posed and additional challenge, resulting in incomplete survey responses. While the educational tool developed for the intervention was picture based, the pre and posttests could not be completed without a minimum 5th grade Spanish literacy level. Although the health fair setting offered convenient access to the target population, it was a distracting environment that limited participants' ability to focus on the educational materials provided and answer the pre and posttests. Finally, the pre/posttest design completed within a short time frame made it difficult to see how much knowledge would be retained by participants over a longer period of time.

\section{Discussion}

Results of the pre/posttest responses show that the application prototype educational tool evaluated in this project was effective in increasing knowledge of diabetes prevention methods. Participants also overwhelmingly expressed interest in having a working DM2 education mobile application available for download on a personal device on the pretest. This demonstrated a strong interest in using a working mobile application for DM2 education materials existed before the intervention took place. Participants showed significant interest in learning more about DM2, as noted from the responses to the open-ended question. These results indicated that the intervention was successful in meeting an educational deficit in the Hispanic community and showed a need for increased education materials to be made available to this population via mobile applications.

In order to address some of the limitations encountered in this project, it will be important for future education trials to establish methods for collecting verbal responses from potential participants who lack the literacy needed to fill out written questionnaires. Another way to include more participants would be to find more optimal settings for delivering the application prototype. Classroom sessions with fewer distractions, or one-on-one counseling, maybe more suitable for implementing the educational app prototype developed in this project.

Additionally, offering a posttest at a longer interval after the intervention would allow for better evaluation of retained knowledge. Pre/posttest designs often show significant response bias and it can be difficult to determine the true measure of change related to the intervention itself. Still, in a 
population with an unknown baseline knowledge, true pretest data collection is helpful in better understanding the demographic and developing further interventions. ${ }^{[20]}$ To further investigate the efficacy of this project's intervention, additional measurements provided by a mixed methods design are indicated.

Nonetheless, the findings of this project indicate significant interest in further development of a working mobile application for widespread use, which is consistent with other studies that have found health modification apps to be widely well received in small trials. ${ }^{[21]}$ Considering the widespread use of smartphones, it is important to look at how these devices can be used to bring reliable health information into the palms of patients. Using the varied mediums offered by technology can help communicate with patients who demonstrate lower literacy skills. ${ }^{[22]}$ While mobile applications for education interventions have been shown to be well received and effective among small samples, further research is needed to evaluate their efficacy and reception among larger sample populations.

\section{CONCLUSiON AND IMPLications FOR PRACTICE}

The results of this project indicated a need for creating a working mobile application that offers culturally tailored DM2 prevention education. As technology continues to play an integral role in modern communication, it is necessary for medical providers to utilize technical applications as a means for increasing patient access to health information. It is important for healthcare systems to view technology not as a separate field of science, rather as a tool to be incorporated into healthcare models in order to connect providers with patients and patients with education.

Combining a culturally tailored approach to DM2 prevention education with a mobile application will allow healthcare providers to incorporate the use of technology for health education in accordance with the Healthy People 2020 goals. The findings of this project demonstrated success in using culturally tailored DM2 education materials when addressing minority populations. It also demonstrated the potential for increasing access to educational materials by making them available through a mobile phone application.

Ultimately, development of a working culturally tailored DM2 prevention educational mobile application could allow for at-risk groups to gain awareness of risk factors and disease prevention and improved self-efficacy. In turn, this could positively impact health outcomes for minorities at highest risk for DM2 in the US. Leveraging technology for healthcare purposes is the next step toward bridging communication gaps and closing healthcare disparities for minority populations.

\section{CONFlicts of InTEREST Disclosure}

The authors declare that there is no conflict of interest.

\section{REFERENCES}

[1] Center for Disease Control and Prevention (September, 2017). Hispanic health. Available from: https://www.cdc.gov/features /hispanichealth/index.html

[2] Piccolo RS, Subramanian SV, Pearce N, et al. Relative contributions of socioeconomic, local environmental, psychosocial, lifestyle/behavioral, biophysiological, and ancestral factors to racial/ethnic disparities in type 2 diabetes. Diabetes Care. 2016; 39(7): 1208-1217. PMid:27330127 https://doi.org/10.2337/ dc15-2255

[3] Ferguson S, Swan M, Smaldone A. Does diabetes self-management education in conjunction with primary care improve glycemic control in Hispanic patients? A systematic review and meta-analysis. The Diabetes Educator. 2015; 41(4): 472-484. PMid:25941192 https://doi.org/10.1177/0145721715584404

[4] Prezio EA, Cheng D, Balasubramanian BA, et al. Community Diabetes Education (CoDE) for uninsured Mexican Americans: a randomized controlled trial of a culturally tailored diabetes education and management program led by a community health worker. Diabetes Research and Clinical Practice. 2013; 100(1): 19-28. PMid:23453178 https://doi.org/10.1016/j.diabres.2013.01.027

[5] Sarkar U, Gourley GI, Lyles CR, et al. Usability of commercially available mobile applications for diverse patients. Journal of Gen- eral Internal Medicine. 2016; 31(12): 1417-1426. PMid:27418347 https://doi.org/10.1007/s11606-016-3771-6

[6] Pu J, Chewning B. Racial difference in diabetes preventive care. Research in Social and Administrative Pharmacy. 2013; 9(6): 790-796. PMid:23246362 https://doi.org/10.1016/j.sapharm. 2012 .11 .005

[7] Govere L, Govere EM. How effective is cultural competence training of healthcare providers on improving patient satisfaction of minority groups? A systematic review of literature. Worldviews on Evidence-Based Nursing. 2016; 13(6): 402-410. PMid:27779817 https://doi.org/10.1111/wvn.12176

[8] Schillinger D, McNamara D, Crossley S, et al. The Next Frontier in Communication and the ECLIPPSE Study: Bridging the Linguistic Divide in Secure Messaging. Journal of Diabetes Research. 2017 https://doi.org/10.1155/2017/1348242

[9] Healthy People (Nov 09, 2018). Health communication and health information objectives. Office of disease prevention and health promotion. Available from: https://www.healthypeople.gov/ 2020/topics-objectives/topic/health-communication -and-health-information-technology/objectives

[10] Hudnut-Beumler J, Po'e E, Barkin S. The use of social media for health promotion in 5 Hispanic populations: a scoping systematic review. JMIR Public Health and Surveillance. 2016; 2(2). 
PMid:27400979 https://doi.org/10.2196/publichealth.5 579

[11] Prins E, Monnat S. Examining associations between self-rated health and proficiency in literacy and numeracy among immigrants and US-born adults: Evidence from the Program for the International Assessment of Adult Competencies (PIAAC). PloS One. 2015; 10(7): e0130257. PMid:26132212 https ://doi .org/10.1371/journa 1.pone. 0130257

[12] De Alba A, Britigan DH, Lyden E, et al. Assessing health literacy levels of Spanish-speaking Hispanic patients in Spanish at federally qualified health centers (FQHCs) in the Midwest. Journal of Health Care for the Poor and Underserved. 2016; 27(4): 1726-1732. PMid:27818434 https : //doi.org/10.1353/hpu.2016.0158

[13] United States Census Bureau. QuickFacts Cincinnati city, Ohio. Available from: https://www.census.gov/quickfacts/cinc innaticityohio\#qf-headnote-b

[14] Statistical Atlas. Overview of Carthage, Cincinnati, Ohio. 2018. Available from: https://statisticalatlas.com/neighborh ood/Ohio/Cincinnati/Carthage/Race-and-Ethnicity

[15] Statistical Atlas. Overview of West Price Hill, Cincinnati, Ohio. 2018. Available from: https://statisticalatlas.com/zip/4 5246/Race-and-Ethnicity

[16] Denyes MJ, Orem DE, Bekel G. Self-care: a foundational science. Nursing Science Quarterly. 2001; 14(1): 48-54. PMid:11873354 https://doi.org/10.1177/089431840101400113

[17] Institute for Healthcare Improvement. Science of improvement: Testing changes. 2019. Available from:
http://www.ihi.org/resources/Pages/HowtoImprove

/Scienceof ImprovementTestingChanges . aspx

[18] American Diabetes Association. Types of carbohydrates. 2015. Available from: http://www.diabetes.org/food-and-fitne ss/food/what-can-i-eat/understanding-carbohydrates /types-of-carbohydrates.html

[19] American Heart Association. American heart association recommendations for physical activity in adults. 2014. Available from: http://www . heart .org/HEARTORG/HealthyLiving/Physi calActivity/FitnessBasics/American-Heart-Associati on-Recommendations-for-Physical-Activity-in-Adult s_UCM_307976_Article.jsp\#.W1ytldhKjOQ

[20] Geldhof GJ, Warner DA, Finders JK, et al. Revisiting the utility of retrospective pre-post designs: the need for mixed-method pilot data. Evaluation and Program Planning. 2018; 70: 83-89. PMid:30029016 https ://doi.org/10.1016/j.evalprogplan.2018.05.002

[21] Payne HE, Lister C, West JH, et al. Behavioral functionality of mobile apps in health interventions: a systematic review of the literature. JMIR mHealth and uHealth. 2015; 3(1): e20. PMid:25803705 https://doi .org/10.2196/mhealth. 3335

[22] Yeung DL, Alvarez KS, Quinones ME, et al. Low-health literacy flashcards \& mobile video reinforcement to improve medication adherence in patients on oral diabetes, heart failure, and hypertension medications. Journal of the American Pharmacists Association. 2017; 57(1): 30-37. PMid:27816544 https ://doi .org/10.1016/j.ja ph. 2016.08 .012 